\title{
A Short Note on Application of Fuzzy and Meta-heuristics Optimization in Manufacturing Environment
}

\section{Pandian Vasant ${ }^{*}$}

Department of Fundamental \& Applied Sciences, Universiti Teknologi PETRONAS, 31750, Tronoh, Malaysia

*Corresponding author: Pandian Vasant, Department of Fundamental \& Applied Sciences, Universiti Teknologi PETRONAS, 31750, Tronoh, Malaysia, Tel: +6053687865, +60164892932; E-mail: pvasant@gmail.com

Received date: August 29, 2014; Accepted date: August 29, 2014; Published date: September 08, 2014

Copyright: (c) Vasant P. This is an open-access article distributed under the terms of the Creative Commons Attribution License, which permits unrestricted use, distribution, and reproduction in any medium, provided the original author and source are credited.

\section{Editorial}

Modern industrial manufacturing problems inevitably faces many challenging problems of fuzziness in various aspects such as raw material availability, human resource availability, processing capability and constraints and limitations imposed by marketing department. This problem can be solved by a methodology which takes care of such fuzziness in the complex systems [1,2]. As the analyst solves this problem, the decision maker and the implementer have to coordinate with the analyst for taking up a decision on a successful strategy for implementation [3]. Such a complex problem of vagueness and uncertainty can be handled successfully by the theory of fuzzy logic and hybrid meta-heuristics optimization approaches.

In this research, a new fuzzy logic based methodology using a specific membership function, named as modified S-curve membership function is proposed [4,5]. The modified S-curve membership function is first formulated and its flexibility in taking up vagueness in parameters is established by an analytical approach. This membership function is tested for its useful performance through an illustrative example by employing fuzzy linear programming [6].

The usefulness of this modified S-curve membership function is further established using a real life industrial production planning of a chocolate manufacturing unit. The unit produces 8 products using 8 raw materials, mixed in various proportions by 9 different processes under 29 constraints. This complex problem has 8 inherent subproblems. A set of solutions to all these sub-problems are achieved thus establishing the usefulness of the suggested membership function for decision making in industrial production planning [7].

Furthermore a non-linear objective function has been formulated to investigate the optimal global solution for the industrial production planning problems. Combination of classical and meta-heuristics techniques have been employed to solve this non-linear objective function problems with 29 constraints [8]. The near global optimal solution has been obtained for this particular problem with respect to vagueness factor and degree of satisfaction. The researchers will benefit a lot from the findings of this research work in terms of theoretical development of fuzzy non-linear membership functions and hybrid meta-heuristics optimization techniques as a cutting hedge knowledge based development in the research area of manufacturing industry and with modern optimization methodologies [9]. The proposed methods, results and findings of this research work has established tremendous achievement in terms of robustness, convenience, diversity, productivity, convergence, flexibility, feasibility, reliability, efficiency, effectiveness, computational time, stability, stopping criteria and computational cost [10-12].

\section{References}

1. Madronero MD, Peidro D, Vasant P (2010) Vendor selection problem by using an interactive fuzzy multi-objective approach with modified scurve membership functions. Computers and Mathematics with Applications 60: 1038-1048.

2. Peidro D, Vasant P (2011) Transportation planning with modified scurve membership functions using an interactive fuzzy multi-objective approach, Applied Soft Computing 11: 2656-2663.

3. Elamvazuthi I, Vasant P, Ganesan T (2010) Fuzzy Linear Programming using Modified Logistic Membership Function, International Review of Automatic Control (IREACO) 3: 370-377.

4. Bhattacharya A, Vasant P (2007) Soft-sensing of level of satisfaction in TOC product-mix decision heuristic using robust fuzzy-LP, European Journal of Operational Research 177: 55-70.

5. Vasant P, Bhattacharya A, Sarkar B, Mukherjee SK (2007) Detection of level of satisfaction and fuzziness patterns for MCDM model with modified flexible S-curve MF. Applied Soft Computing Journal 7: 1044-1054.

6. Vasant P, Elamvazuthi I, Ganesan T, Webb JF (2010) Iterative fuzzy optimization approach for crude oil refinery industry. Scientific Annals of Computer Science 8: 262-280.

7. Vasant P (2012) Novel Meta-Heuristic Optimization Techniques for Solving Fuzzy Programming Problems. In M. Khan, \& A. Ansari (Eds.) Handbook of Research on Industrial Informatics and Manufacturing Intelligence: Innovations and Solutions (pp. 104-131). Hershey, PA: Information Science Reference.

8. Vasant P (2013) Hybrid Linear Search, Genetic Algorithms, and Simulated Annealing for Fuzzy Non-Linear Industrial Production Planning Problems. In P. Vasant (Ed.), Meta-Heuristics Optimization Algorithms in Engineering, Business, Economics, and Finance (pp. 87-109). Hershey, PA: Information Science Reference.

9. Vasant P, Barsoum N (2009) Hybrid genetic algorithms and line search method for industrial production planning with non-linear fitness function. Engineering Applications of Artificial Intelligence 22: 767-777.

10. Vasant P (2012) Solving Fuzzy Optimization Problems of Uncertain Technological Coefficients with Genetic Algorithms and Hybrid Genetic Algorithms Pattern Search Approaches. In P. Vasant, N. Barsoum, \& J. Webb (Eds.), Innovation in Power, Control, and Optimization: Emerging Energy Technologies (pp. 344-368).

11. Tsoulos IG, Vasant P (2010) Product mix selection using an evolutionary technique. AIP Conference Proceedings 1159: 240-247.

12. Vasant PM (2003) Application of fuzzy linear programming in production planning. Fuzzy Optimization and Decision Making 2: 229-241. 